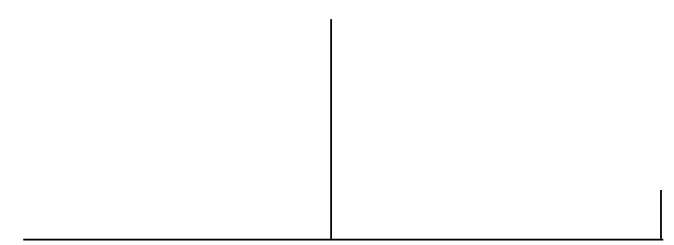

Rev. Latinoam. Psicopat. Fund., São Paulo, v. 13, n. 3, p. 457-468, setembro 2010

\title{
A arte de morar... na Lua: a construção de um novo espaço de morar frente à mudança do dispositivo asilar para o Serviço Residencial Terapêutico*
}

Tania Kuperman Sztajnberg Maria Tavares Cavalcanti

Em instituições que funcionam sob a lógica da desinstitucionalização existe um número significativo de pacientes que permanecem nos hospitais psiquiátricos. A implantação dos Serviços Residenciais Terapêuticos tornouse uma das principais estratégias da reforma psiquiátrica. A partir do estudo de um caso clínico e os enfrentamentos encontrados neste trabalho, no que tange a passagem da internação ao SRT, aponto para a necessidade de uma escuta clínica que propicie a invenção de um espaço subjetivo que permitirá alguma circulação entre os dispositivos.

Palavras-chave: Psicose, psicanálise, desinstitucionalização, Serviço Residencial Terapêutico

* Trabalho desenvolvido a partir do grupo de pesquisa supervisionado pela Profa. Dra. Maria Tavares Cavalcanti, consistindo no estudo do material teórico e reflexão sobre $\mathrm{o}$ atendimento e assistência à clientela do Instituto de Psiquiatria da Universidade Federal do Rio de Janeiro - IPUB/UFRJ e seu acompanhamento no processo de desinstitucionalização e na implantação de residências terapêuticas e apresentado no III Congresso Internacional de Psicopatologia Fundamental/IX Congresso Brasileiro de Psicopatologia Fundamental, realizado na Universidade Federal Fluminense, Niterói, RJ, no período compreendido entre 4 e 7 de setembro de 2008. 


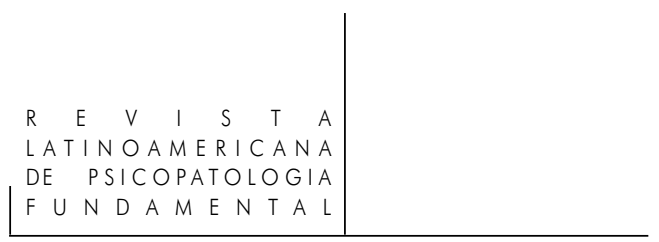

\begin{abstract}
Perdi alguma coisa que me era essencial, e que já não me é mais... assim como se eu tivesse perdido uma terceira perna que até então me impossibilitava de andar mas que fazia de mim um tripé estável. Esta terceira perna eu perdi e voltei a ser uma pessoa que nunca fui. Voltei a ter o que nunca tive: apenas duas pernas.
\end{abstract}

(Clarice Lispector, A paixão segundo G.H.)

Neste trabalho apresento o caso clínico de uma paciente e o acompanhamento do seu processo de saída da enfermaria de crise de um hospital psiquiátrico para um Serviço Residencial Terapêutico (SRT). A partir do estudo deste caso clínico, pretendo elucidar as questões relativas ao dispositivo da reforma psiquiátrica em discussão, no que envolve a passagem de um dispositivo ao outro. Para desenvolver esta proposta, enfrentaremos as diferentes lógicas, tanto política quanto clínica, sob a tentativa de um olhar de um dos maiores interessados. Apresento, assim, uma moradora de um SRT, o caminho percorrido ao final de sua longa internação e a contínua inserção neste serviço ainda em acompanhamento.

A paciente, que chamarei aqui de Marilena, estava na enfermaria de crise do Instituto de Psiquiatria da Universidade Federal do Rio de Janeiro (IPUB) há alguns anos. ${ }^{1}$ Começamos nossos encontros ainda durante a internação, mas a perspectiva de mudança para a Residência Terapêutica (RT) já se aproximava.

Marilena passou a se enquadrar no perfil dos pacientes indicados para a RT: não se tratava de uma paciente em situação de crise, mas, assim como muitos pacientes, encontrava-se de alguma maneira aprisionada ao circuito psiquiátrico, de modo que estava há mais de um ano na enfermaria de crise do IPUB. Além disso, não possuía nenhum vínculo familiar que tivesse concretizado sua saída da instituição.

Entretanto, por que haveria Marilena de sair da instituição psiquiátrica? Seria a enfermaria de crise de um hospital psiquiátrico o lugar que Marilena

1. O Instituto de Psiquiatria da UFRJ possui duas enfermarias para pacientes agudos, com tempo médio de internação de 19 dias, no entanto, alguns pacientes, por motivos variados, acabam permanecendo longos períodos internados. 


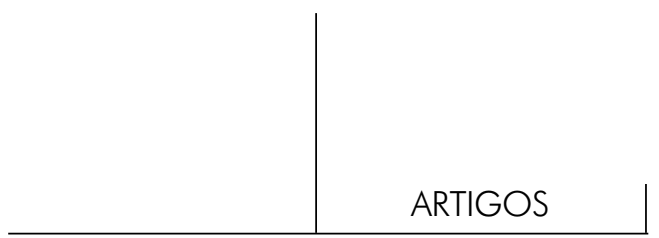

escolheu para morar, ou será que não teve escolha? E ainda, será que ela realmente morava na enfermaria de crise ou lá estava apenas de passagem, mesmo que por longo período?

Ao que tudo indica, esta enfermaria deveria ser um lugar de passagem. Lugar onde a lei, a ideologia e o conhecimento teórico/prático preconizam permanência limitada a um curto período determinado pela crise. Não existe nenhuma inscrição que aponte que aquele lugar poderia servir de moradia. Os pacientes não possuem armários e não há nenhum pertence que não esteja protegido pelo próprio corpo embaixo dos colchões. Todavia, existem aqueles pacientes que lá chegaram e não mais saíram. ${ }^{2}$

Hoje, em linhas reconhecidas por lei pelo Sistema Único de Saúde (SUS), a moradia é um direito de qualquer cidadão. Entretanto, para o paciente com transtorno mental, tal direito não está apenas relacionado à inclusão desta clientela aos direitos naturais de qualquer cidadão. Neste caso, o lugar de moradia destes pacientes está incluído no projeto terapêutico desta clientela. Para muitos dos que estão no hospital, o Serviço Residencial Terapêutico é a única alternativa possível, a única porta de saída do dispositivo asilar.

Não tenho a intenção de discutir neste trabalho as ambiguidades existentes entre o espaço de morar e o espaço de tratamento. Poderia parecer natural concluir que sair de uma instituição psiquiátrica e poder morar em sua própria casa deveria fazer parte do desejo de cada um destes pacientes. Todavia, afirmo que a experiência de habitar um espaço, mesmo que pareça natural para a maioria de nós, não é algo puro e simples e está intimamente ligado à experiência de existir.

Além disso, considero que a possibilidade deste processo está inteiramente ligada a uma intervenção clínica, ou seja, que o processo de passagem é único para cada paciente e que visa o projeto terapêutico voltado para a singularidade de cada sujeito.

Sob a perspectiva de que o dispositivo asilar é regido por uma lógica de funcionamento e política diferente do SRT, é possível concluir que toda passagem deste paciente, de um dispositivo a outro, não se dá de forma tão fácil. Isso sem levar em conta toda a dificuldade prática que envolve esta mudança tais como o aluguel de imóvel e a compra de móveis e utensílios necessários.

O que poderia então auxiliar ou mesmo marcar a diferença que existiria entre estes dois espaços? O que poderia servir de contraponto ao tratamento mas-

2. Ao longo dos anos, há sempre cerca de 19 a 21 pacientes que encontram-se internados há mais de um ano (aproximadamente $20 \%$ dos pacientes internados) o que nos aponta para dificuldade de estabelecer projetos que possibilitem a saída da internação. 
sificado dos hospitais psiquiátricos? Acredito que para cada um destes pacientes o significado da instituição - e consequentemente seu egresso - toma características singulares nas quais sair da instituição estaria na dependência da presença de alguém que legitime e acolha a singularidade, que possa representar os preceitos de uma nova lógica, bem como acolher e respeitar os limites para a ação deste projeto.

Dentro desta perspectiva fui incumbida de fazer o acompanhamento de Marilena desde o interior da enfermaria, prosseguindo em sua mudança para a moradia a fim de mediar e avaliar este processo de acordo com suas possibilidades.

Durante o período de internação, Marilena era uma paciente que tinha grande circulação pelo pátio e outros espaços do IPUB. Conhecia grande parte das pessoas que ali trabalhava e comunicava-se com quem passava por lá. Era conhecida por pedir um real a quem encontrava e, com o dinheiro que conseguia, comprava cigarro, lanche e café na lanchonete do Instituto.

Por opção, preferiu não participar da maior parte dos encontros do grupo que estava acompanhando os pacientes que iriam para a moradia, pois sempre que eu tentava chamá-la, estava dormindo ou dizia estar tonta e com sono. Depois do horário do grupo, quando já estava acordada, Marilena sempre podia ser encontrada andando pelo pátio do IPUB. Conversávamos e ela sempre trazia questões que eu identificava como referentes à moradia ou à saída do hospital. Certa vez perguntou: "É verdade o que ouvi dizer que rei no Brasil não manda mais nada, quem manda é o presidente?" Ao receber a resposta de que ela tinha razão, Marilena responde parecendo angustiada: "O que eu vou fazer agora, se o rei não manda mais nada, pra que eu vou ser rei?" Perguntada para que gostaria de ser rei, ela diz que faria tudo diferente, que daria roupa, comida e sapato para as pessoas. Marilena começa a repetir que "é um fracasso, que o presidente está querendo prendê-la no hospital e se não consegue nem sair sozinha do hospital, como vai mandar no país inteiro". Ao ouvir, afirmo também estar lá para ajudá-la a sair do hospital, mas Marilena diz não querer ir para esta casa, pois "tem vários castelos e não quer ir para casa que só cabe uma pessoa e querem colocar seis".

Em uma de suas únicas participações no grupo, fica bastante animada com a proximidade da saída, pois um dos pacientes já havia se mudado para a casa. Diz que para se mudar para a casa vai precisar de uma mesa, cadernos, livros e uma Bíblia, pois precisa fazer seus estudos sobre "a existência humana", "como chegar a Deus sem precisar morrer" e "como chegar ao Sol e extrair ouro".

Marilena foi uma das primeiras pacientes a se tornar moradora da mais recente RT do IPUB. ${ }^{3}$ Logo no início já se via grande diferença no seu modo de se

3. Até o presente momento existem três SRT vinculados ao IPUB inaugurados em 2000, 2003 e 2004.

Rev. Latinoam. Psicopat. Fund., São Paulo, v. 13, n. 3, p. 457-468, setembro 2010 


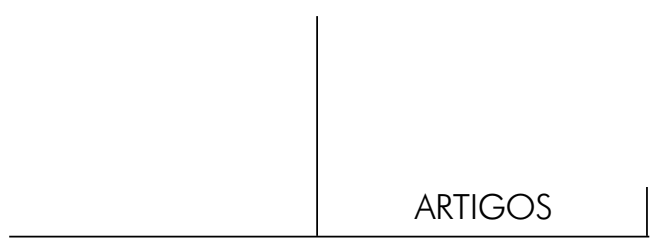

apresentar: Já estava recebendo o benefício do Programa de volta para casa ${ }^{4}$ e parecia mais animada, se arrumando com suas roupas novas compradas a seu gosto.

Em nosso primeiro encontro na moradia, Marilena conta como foi parar no IPUB. Diz que ficava na Praia do Flamengo gritando "verdades", pois precisava dizer para as pessoas "como se constrói casas na Lua" e me pede um caderno e livros para continuar estes estudos. No encontro seguinte era seu aniversário, dou para ela um caderno e ganha também, de outra acompanhante, dois livros sobre o corpo humano que ela disse ser exatamente o que precisava. A Bíblia - presente de outro acompanhante - recusou por ser muito pequena. Algumas vezes em que retornei a casa, encontrei-a sentada à mesa, escrevendo em seu caderno o que explicou ser seus estudos sobre a casa na Lua. Argumentou a relevância destes estudos explicando que "se falta terra para as pessoas morarem é importante saber construir casas na Lua".

Freud, em alguns de seus textos, afirma que, para o psicótico, o delírio se apresenta como tentativa de cura. Acredito que os estudos sobre as "formas de morar na Lua" podem ser considerados tentativas que a própria Marilena encontrou para estar em sua nova moradia e no mundo. No texto "Neurose e psicose" (1924/1923), o autor aponta:

Com referência à gênese dos delírios, inúmeras análises nos ensinaram que o delírio se encontra aplicado como um remendo no lugar em que originalmente uma fenda apareceu na relação do ego com o mundo externo. Se essa precondição de um conflito com o mundo externo não nos é muito mais observável do que atualmente acontece, isso se deve ao fato de que, no quadro clínico da psicose, as manifestações do processo patogênico são amiúde recobertas por manifestações de uma tentativa de cura. (p. 169)

Entretanto, Marilena não parava de repetir o quanto sentia falta do IPUB. Questionava sobre a possibilidade de voltar a morar na enfermaria. Era categórica ao afirmar sua preferência por morar no hospital. Passou a ocupar seu dia dormindo em sua cama. Recusava-se a frequentar o Centro de Atenção Diária (CAD) de referência para seu tratamento, que funcionava no interior do IPUB. Conversar com ela era possível apenas na hora do almoço, quando acordava para fumar ou quando combinávamos de comprar roupas novas. Para esta combinação, a encontrava pronta à minha espera, aguardando a saída. A qualquer outra proposta, se dizia tonta ou com dor nos ossos.

4. Programa destinado ao auxílio financeiro mensal para pacientes usuários do SRT ou que retornam para suas famílias, egressos de internação superior a três anos em hospital psiquiátrico até $\mathrm{o}$ ano de 2003. 


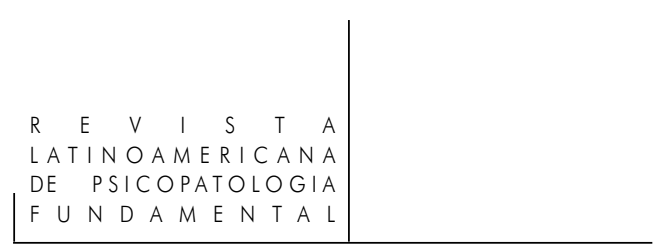

Comparativamente à sua circulação e aos laços estabelecidos durante seu longo período de internação, Marilena passou pelo processo inverso do que é inicialmente esperado do processo de mudança do hospital para a moradia. Seu dia a dia passou a ser bem mais restrito e ficava na cama a maior parte do dia, assim como grande parte dos pacientes que encontramos internados em instituições psiquiátricas.

Por iniciativa própria, Marilena passou a frequentar o CAD e consequentemente o IPUB (ou talvez o inverso: IPUB e consequentemente o CAD). Comparece religiosamente toda semana no dia combinado durante toda a tarde em que boa parte circula pelo pátio do IPUB. Quer comprar roupas novas para este momento e fala sobre a necessidade de receber mais dinheiro para seus gastos deste dia sob o argumento de que esta "é sua maior diversão". Marilena continua passando grande parte do dia deitada na cama, mas desde que voltou a frequentar o IPUB faz tempo que não menciona a vontade de lá residir. Quando questionada sobre este assunto, ela diz que não pretende mais voltar, porque lá as pessoas batiam nela e chegaram a quebrar todos os seus ossos. Marilena diz que os enfermeiros "batiam nela, quebraram seu pescoço, pernas, braços e, até hoje, ainda sente as dores". Diz que gastava todo o seu dinheiro comprando cigarros, pois tinha que dá-los para outros pacientes, já que, segundo ela, apanhava deles caso não desse.

Ao ser indagada se hoje em dia ainda tem que dar seus cigarros quando vai ao IPUB ela responde que não, que hoje em dia quando vai ao IPUB vai bem vestida e as pessoas sabem que ela não mora mais lá, por isso a respeitam. Perguntada sobre o que gosta de fazer no IPUB, ela diz que gosta de fazer lanche na lanchonete do IPUB e encontrar as pessoas. Questionada sobre a diferença entre fazer um lanche nesta lanchonete ou na padaria perto de sua casa, Marilena diz que não sabe.

Qual seria então esta diferença? Quando a encontro andando pelo hospital, está toda arrumada, com roupas novas e bijuterias, mas passa parte do dia deitada nos bancos de concreto do pátio. Imagem bastante ambígua, que facilmente pode nos levar ao que acredito ser uma conclusão equivocada, de que esta passagem pelo hospital não exerce para ela nenhuma função. Não é possível negar que o hospital faz parte de sua história. Para esta paciente, estar no IPUB não significa estar em qualquer lugar, mas sim em um lugar onde se reconhece e é reconhecida.

No texto "Hóspedes e peregrinos, duas montagens subjetivas na psicose", Adriana Cerdeira e Guilherme Gutman (2006) discutem que a diferença entre estas duas categorias se apresenta na posição subjetiva, na maneira que o psicótico encontra de estar no mundo. Para tal eles apresentam dois casos em que, à sua maneira, cada qual encontrou seu lugar de hóspede, seja fora ou dentro do circuito psiquiátrico. Para estes autores tais diferenças são tratadas da seguinte forma: 
... as ideias de hospedagem e de peregrinação entendidas como realidades psíquicas que indicam, respectivamente, o caminho em direção a algum lugar de estabilidade mínima ou trânsito por circuitos imprecisos... Por esse motivo aquilo que vai caracterizar alguém como hóspede ou peregrino não é o lugar em que vive, mas os entrecruzamentos de sua rede subjetiva com seus pontos de voo e pouso. (p. 670)

Para Winnicott (1975), o processo criativo é derivado da relação primordial entre mãe e bebê. Para sustentar sua formulação, o autor apresenta o que denominou de "objetos e fenômenos transicionais" para indicar a fase do processo de subjetivação em que o infans habita um espaço intermediário entre a realidade interna e a vida externa. Segundo o autor, estes fenômenos circulam entre o que se reconhece como si mesmo e o que se diferencia como não eu.

Em Winnicott, o desenvolvimento emocional primitivo segue um percurso no sentido da experimentação sensorial desde o que é inteiramente subjetivo até o que é objetivamente percebido. Para que a exterioridade seja reconhecida, é preciso que o sujeito use o objeto, teste a resistência dele aos seus ataques e, a partir da sobrevivência dele torna-se capaz de discriminar o que é eu e não eu. No início, antes de todo esse processo acontecer, Winnicott (1975) descreve um momento originário de ilusão de onipotência. Para ele, essa experiência decorre do paradoxo de que o objeto está lá para ser criado pelo bebê. Não se trata, portanto, de um encontro, mas de uma invenção da qual a criança se apropria. Daí advém o existir originário que se dá na área intermediária entre a criatividade primária e a percepção objetiva.

No momento posterior o bebê passa pelo processo de desilusão da onipotência, promovida pela falha do ambiente que faz surgir, na relação mãe-bebê, um espaço para a diferenciação. É essa experiência que vai marcar a diferença entre o eu e o não eu, e o decorrente reconhecimento de uma alteridade. Nas palavras do autor:

Desde o nascimento, portanto, o ser humano está envolvido com o problema da relação entre o que é objetivamente percebido e aquilo que é subjetivamente concebido e, na solução desse problema, não existe saúde para o ser humano que não tenha sido iniciado suficientemente bem pela mãe. A área intermediária a que me refiro é a área que é concedida ao bebê entre a criatividade primária e a percepção objetiva baseada no teste de realidade. Os fenômenos transicionais representam os primeiros estádios do uso da ilusão sem os quais não existe para o ser humano, significado na ideia de uma relação com um objeto que é por outros percebido como externo a este ser. (p. 26)

Se o processo de desilusão se realiza de maneira satisfatória, para Winnicott instala-se um desenvolvimento saudável da vida emocional do sujeito. A mesma 
mãe que, empatizada com o bebe, possibilita a ilusão, é a que favorece, ao longo de um delicado e gradativo processo de separação, o processo de desilusão. Só a partir deste primeiro momento de afinação mãe-bebê, em que ela reconhece o tempo subjetivo e as minúcias do seu bebê, é que a desilusão pode ocorrer gradativamente gerando a transição para o que é objetivamente compartilhado. Entretanto, esta passagem não se dá de forma completa e definitiva, ao longo da vida do sujeito alguma circulação sempre se dá entre este dois momentos. Ainda nas palavras de Winnicott (1975):

Se um adulto nos reivindicar a aceitação da objetividade de seus fenômenos subjetivos, discerniremos ou diagnosticaremos nele loucura. Se, contudo, o adulto consegue extrair prazer da área pessoal intermediária sem fazer reivindicações podemos então reconhecer nossas próprias e correspondentes áreas intermediárias, sendo que nos apraz descobrir certo grau de sobreposição, isto é, de experiência comum entre membros de um grupo de arte, na religião, ou na filosofia. (p. 29)

Encontrar o lugar de sobreposição seria então uma saída possível? A resposta positiva estaria somente no lugar inventado, que amplia possibilidades de estar no mundo.

Do mesmo modo como o início da vida do sujeito depende das condições do ambiente, proporcionadas pela relação mãe-bebê, é necessária, em um dispositivo de saúde mental, a existência de um espaço que seja vivido como um lugar onde a experimentação daquilo que faltou anteriormente lhe seja agora permitida. É nesta tentativa de recobrir a falha original que se cria, pela primeira vez, as condições para que este sujeito se legitime.

Vale dizer que não se trata de defender a institucionalização. Ao contrário, refiro-me a um lugar que não se reduz ao hospital, tampouco aos serviços substitutivos. Um lugar inventado que se reporta mais ao uso que se faz de qualquer um ou de nenhum destes serviços. Todavia, não é fácil encontrar este lugar, este espaço potencial, que constitui o paradoxo de se encontrar o que está lá para ser criado. Condição que depende de uma relação e escuta deste sujeito que proporciona o encontro. A quem então será designada esta "função materna"? Ao que tudo indica, esta função será estabelecida com aquele que tiver alguma possibilidade de se adequar a este tipo de condição, seja um técnico de referência, um serviço ou uma instituição.

No caso da paciente em questão, o espaço psiquiátrico propiciou uma certa identidade, mesmo que incipiente, criada na relação com a instituição onde foi possível algum endereçamento. Em discussão com grupo de pesquisa do IPUB, que acompanha os pacientes moradores do SRT, nos perguntávamos por que Marilena, mesmo com dificuldade de chegar ao hospital, insistia em frequentar o 


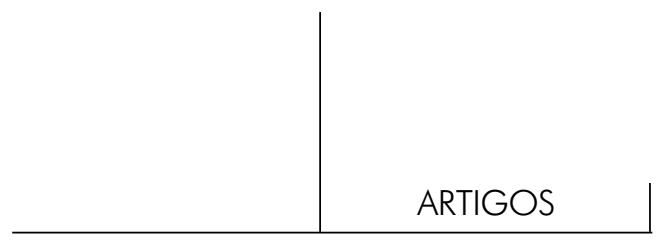

bar dentro da instituição, mesmo havendo tantos que se situam nas redondezas da moradia. Entre diferentes opiniões sobre o vínculo da paciente com a instituição, concordamos que apesar dos avanços no processo de inclusão do paciente psiquiátrico na sociedade, é possível citar inúmeros exemplos daqueles que não se sentem incluídos e não se sentem capazes de entrar em um bar, loja ou restaurante por conta própria, pois sabem que irão se deparar com o estranhamento.

Pode-se observar que mesmo que estes pacientes estejam do lado de fora das grades do asilamento, não estão livres dos muros da proteção. Entretanto, cabe-nos perguntar se este muro é construído pela equipe protetora ou trata-se de uma necessidade criada pela estrutura psicótica. Como representantes da equipe de trabalho da saúde mental, mesmo que em nome do processo de desinstitucionalização, somos chamados a responder por aquilo que se proporciona na ética do cuidado e que o espaço social não garante.

Quando fala em moradia, é a uma ameaça persecutória que Marilena se refere. Diz que lá está sempre em risco: "a mesa pode cair a qualquer momento e cortar as pernas", "o banheiro é uma bomba que pode explodir...". Sempre existem ladrões e criminosos que estão a sua procura, atrás do seu saber, seu dinheiro ou dos seus ossos. Eu, como visitante, pergunto o que posso fazer para ajudá-la a se proteger e indago a quem podemos, então, pedir ajuda.

Marilena começou a escrever o que chamou de "ciência-pesquisa". Escreve em seu caderno sobre os temas mais diversos: casas na Lua, instruções de como passar creme, alertas sobre ladrões e assassinos estão enunciados e refletem toda a sorte de pensamentos que lhe acometem. Aguarda a minha chegada semanal e pede para que eu "traduza" seus escritos, o que significa ditar-me palavras soltas do seu trabalho para que eu as reescreva. Minha "tradução" é então anexada junto à papelada que é entregue ao segurança da porta de entrada do IPUB. Parece, mesmo por algum tempo, que é na figura concreta daquele que representa tanto a passagem entre o dentro ou fora da instituição quanto algum tipo de segurança daquele espaço, que Marilena constrói alguma possibilidade de circular entre estes dois espaços.

No entanto esta saída encontrada pela paciente é fluida, podendo, a qualquer momento, distanciar-se do ponto de ancoragem onde a ilusão de onipotência encontra seu refúgio. Nestes termos apontamos a questão do que é possível o ambiente proporcionar para que se favoreça a migração do sujeito do refúgio da ilusão de onipotência para a realidade do mundo. Podemos pensar na instituição como mediador desta restituição?

Neste sentido, a paciente passa a utilizar a instituição psiquiátrica como meio de reinvenção do espaço de morar. É neste espaço potencial que se inventa um "lugar" onde o existir verdadeiramente se viabiliza na livre circulação do dentro 


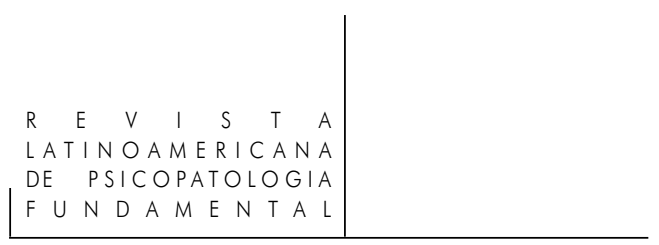

e fora no processo de subjetivação. Talvez esta seja a marca que diferencie este espaço da instituição asilar: aqui as portas estão abertas para entrar ou sair.

Marilena ensinou-me que ainda existe outra possibilidade de morar, que não se encontra nem no dispositivo asilar e nem no SRT, podendo estar entre estes dois, e que só precisa ser inventado. O que nos resta é reconhecer este espaço intermediário para aprender a utilizar e construir nele um espaço clínico.

Termino com um diálogo entre mim e Marilena, após o falecimento de uma das moradoras: M. pergunta-me por que estou triste, quando respondo, ela me consola: "Não fique triste, ela não morreu, saiu daqui feliz da vida para morar num castelo. Você não gostaria de morar num castelo?" Digo que se morar em um castelo significa não encontrar mais nenhuma das pessoas que gosto preferiria ficar onde estou, ao que M. me responde: "A vida é assim, quando casamos temos que largar nossos pais, para morar em um castelo temos que largar todo o resto". Sábias palavras de quem sabe que, rendido à condição psicótica, é difícil não estar sujeito a uma peregrinação solitária.

\section{Referência Documental}

Ministério da Saúde. Portaria n ${ }^{\circ}$ 106/MS, de 11 de fevereiro de 2000.

\section{Referências}

BARRETO, K. D. Ética e técnica no acompanhamento terapêutico, andanças com Dom Quixote e Sancho Pança. São Paulo: Unimarco, 2000.

Cavalcanti, M. T.; Vilete, L.; Sztajnberg, T. K. Casa e/ou Serviço? O dilema das moradias assistidas e/ou Serviços Residenciais Terapêuticos no contexto da Reforma psiquiátrica brasileira. Cadernos do IPUB, Rio de Janeiro, n. 22 - Desinstitucionalização. A experiência dos Serviços Residenciais Terapêuticos, 2006.

Cerdeira, A.; Gutman, G. Hóspedes e peregrinos duas montagens subjetivas na psicose. Revista Latinoamericana de Psicopatologia Fundamental, São Paulo, ano IX, n. 4, p. 668-675, dez. 2006.

Freud, S. (1924). A perda da realidade na neurose e na psicose. In: Edição Standard Brasileira das Obras Psicológicas Completas de Sigmund Freud. Rio de Janeiro: Imago, 1988. v. XIX. . (1924). Neurose e psicose. In: Edição Standard Brasileira das Obras Psicológicas Completas de Sigmund Freud. Rio de Janeiro: Imago, 1988. v. XIX. 


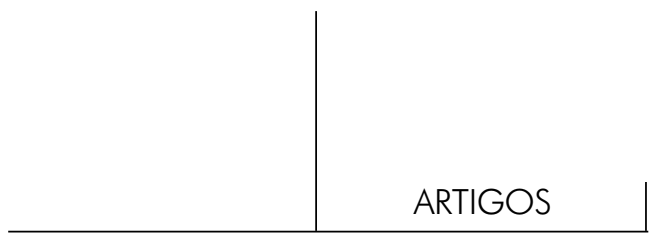

Lispector, C. A paixão segundo G.H. Rio de Janeiro: Francisco Alves, 1991.

WinnicotT, D. W. O brincar e a realidade. Rio de Janeiro: Imago, 1975.

\section{Resumo}

(The art of living ... on the Moon: the construction of a new place to live, in view of changes from asylum-type living to a therapeutic residence)

Despite the fact that numerous hospital institutions are now operating under the logic of deinstitutionalization, many patients continue to live in them. Therapeutic residences have become a leading strategy in the psychiatric reform. A case study on the challenges faced in the transition from hospitalization to residential care serves as the point of departure, from there I discuss the need for clinical listening that is conducive to the creation of a subjective space that will allow for the circulation between one situation and the other.

Key words: Psychosis, psychoanalysis, deinstitutionalization, therapeutic residence

(L'art d'habiter...dans la Lune: la construction d'un nouvel espace d'habitation face au changement de l'asile comme appareil au Service Résidentiel Térapeutique)

Même dans des hôpitaux psychiatriques qui opèrent dans la logique de la courte permanence, un nombre important de patients y demeurent. La mise en place de Services Résidentiels Thérapeutiques est devenue l'une des principales stratégies de la réforme psychiatrique. À travers l'étude d'un cas clinique, surtout lors d'une hospitalisation dans un SRT et des questions qui ont surgi pendant ce travail, nous proposons la nécessité d'une écoute clinique qui facilite l'invention d'un espace subjectif qui permettra une circulation entre les différents services.

Mots clés: Psychose, psychanalyse, Service Résidentiel Thérapeutiques

(A arte de habitar... en la Luna: la construcción de un nuevo espacio de habitación frente al cambio del dispositivo asilar para el Servicio Residencial Terapéutico)

En instituciones que funcionan de acuerdo con la lógica de la hospitalización de corta permanencia hay un número significativo de pacientes que aún permanece en los hospitales psiquiátricos. La implantación y aplicación de los Servicios Residenciales Terapéuticos se constituyó en una de las principales estrategias de la reforma psiquiátrica. A partir del estudio de un caso clínico y centrándome en las cuestiones surgidas en dicho trabajo en lo que concierne a la transición de la hospitalización a la atención domiciliar (SRT), destaco y propongo la necesidad de una escucha clínica 


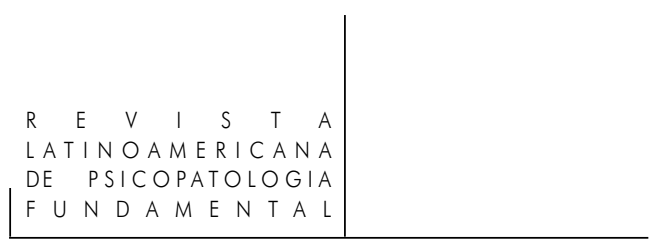

que propicie la invención de un espacio subjetivo que permita una circulación entre los diferentes servicios.

Palabras claves: Psicosis, psicoanálisis, Servicio Residencial Terapéutico

Citação/Citation: Sztajnberg, T.K.; CAVAlCanti, M.T. A arte de morar... na Lua: a construção de um novo espaço de morar frente à mudança do dispositivo asilar para o Serviço Residencial Terapêutico. Revista Latinoamericana de Psicopatologia Fundamental, São Paulo, v. 13, n. 3, p. 457-468, set. 2010 .

Editor do artigo/Editor: Prof. Dr. Manoel Tosta Berlinck

Recebido/Received: 1.7.2009/7.1.2009 Aceito/Accepted: 18.10.2009/ 10.18.2009

Copyright: () 2009 Associação Universitária de Pesquisa em Psicopatologia Fundamental/ University Association for Research in Fundamental Psychopathology. Este é um artigo de livre acesso, que permite uso irrestrito, distribuição e reprodução em qualquer meio, desde que o autor e a fonte sejam citados/This is an open-access article, which permits unrestricted use, distribution, and reproduction in any medium, provided the original author and source are credited.

Financiamento/Funding: As autoras declaram não ter sido financiadas ou apoiadas/The authors have no support or funding to report.

Conflito de interesses/Conflict of interest: As autoras declaram que não há conflito de interesses/The authors declare that has no conflict of interest.

\section{TANia KuPERman SzTajnBERg}

Psicóloga especialista em Saúde Mental pela SMS/RJ nos moldes da residência pela Secretaria Municipal de Saúde do Rio de Janeiro (Rio de Janeiro, RJ, Brasil), em estágio probatório para mestrado no Instituto de Psiquiatria da Universidade Federal do Rio de Janeiro - IPUB/UFRJ (Rio de Janeiro, RJ, Brasil); Supervisora/Acompanhante Terapêutica das Residências Terapêuticas do eixo do Encantado/Equipe de Segmento do CAPS Clarice Lispector - Engenho de Dentro (Rio de Janeiro, RJ, Brasil).

Rua Maria Angélica, 270/306 - Jardim Botânico

22461-152 Rio de Janeiro, RJ, Brasil

Fone: (21) 2535-3555

e-mail: tania.kuperman@gmail.com

\section{Maria Tavares Cavalcanti}

Professora associada do Depto. de Psiquiatria e Medicina Legal da Faculdade de Medicina da Universidade Federal do Rio de Janeiro - UFRJ (Rio de Janeiro, RJ, Brasil); Vice-diretora clínica do Instituto de Psiquiatria da mesma universidade.

Av. Portugal, 884/101 - Urca

22291-050 Rio de Janeiro, RJ, Brasil

Fone: (21) 9349-0918

e-mail: mariatavarescavalcanti@gmail.com 